\title{
Parcelamento de doses de $\mathrm{K}_{2} \mathrm{O}$ sobre a produção de feijão-caupi
}

\author{
Splitting and $\mathrm{K}_{2} \mathrm{O}$ doses on cowpea production \\ A. M. N. M. Guerra*; M. G. M. Silva; R. S. Evangelista; E. B. Santos \\ Centro Multidisciplinar de Barra, Universidade Federal do Oeste da Bahia - UFOB/Barra, 47100-00, Barra-BA, \\ Brasil \\ *mirianagronoma@hotmail.com
}

(Recebido em 25 de fevereiro de 2020; aceito em 19 de agosto de 2020)

\begin{abstract}
Objetivou-se avaliar o efeito da forma de parcelamento das doses de fertilização potássica sobre a produção de feijão-caupi cultivar Pingo de Ouro. O trabalho foi realizado na Universidade Federal do Oeste da Bahia, em Barra (BA), no período de agosto a outubro de 2018. O delineamento experimental foi em blocos casualizados, no esquema fatorial $2 \times 5$, compreendendo dois modos de aplicação da adubação potássica (toda a dose em fundação e parcelado com $1 / 2$ em fundação e a outra $1 / 2$ em cobertura no início do florescimento) e cinco doses de $\mathrm{K}_{2} \mathrm{O}\left(0,40,60,80\right.$ e $100 \mathrm{~kg} \mathrm{ha}^{-1}$ de $\left.\mathrm{K}_{2} \mathrm{O}\right)$, com quatro repetições. Cada parcela foi composta por 20 plantas espaçadas de $0,50 \mathrm{~m}$ x $0,20 \mathrm{~m}$. O parcelamento da dose de $100 \mathrm{~kg} \mathrm{ha}^{-1}$ propocionou a produção de aproximadamente 22 vagens por planta. O fornecimento de toda à adubação potássica em fundação no sulco de semeadura proporcionou aumento de 6,67\% no número de vagens por planta em comparação com as plantas que tiveram a adubação parcelada. As produções máximas de vagens por planta $(3,3)$, número de grãos por vagem $(17,5)$, massa de 10 vagens secas $(50 \mathrm{~g})$, massa de grãos secos de 10 vagens ( $30 \mathrm{~g})$ e produtividade de grãos secos $\left(2,4 \mathrm{t} \mathrm{ha}^{-1}\right)$ foram obtidas, respectivamente com 60, 100, 60,100 e $60 \mathrm{~kg} \mathrm{ha}^{-1}$ de $\mathrm{K}_{2} \mathrm{O}$. Destaca-se que o fornecimento da adubação potássica de modo parcelado no cultivo de feijoeiro caupi seja mais adequado e racional, pois o nutriente estará disponível no momento de maior demanda metabólica das plantas e também, serão evitadas perdas por lixiviação no solo.

Palavras-chave: Fertilização potássica, produção de grãos secos, Vigna unguiculata.
\end{abstract}

The objective of this study was to evaluate the effect of the form of splitting potassium fertilization doses on the production of cowpea cultivar Pingo de Ouro. The work was carried out at the Federal University of Western Bahia, in Barra (BA), from August to October 2018. The experimental design was in randomized blocks, in a $2 \times 5$ factorial scheme, comprising two modes of application of potassium fertilization (all the dose in foundation and split with $1 / 2$ in foundation and the other $1 / 2$ in cover at the beginning of flowering) and five doses of $\mathrm{K}_{2} \mathrm{O}\left(0,40,60,80\right.$ and $100 \mathrm{~kg} \mathrm{ha}^{-1}$ of $\left.\mathrm{K}_{2} \mathrm{O}\right)$, with four replications. Each plot was composed of 20 plants spaced $0.50 \mathrm{~m} \times 0.20 \mathrm{~m}$ apart. The split of the $100 \mathrm{~kg} \mathrm{ha}^{-1}$ dose led to the production of approximately 22 pods per plant. The supply of all the potassium fertilization in foundation in the sowing furrow provided an increase of $6.67 \%$ in the number of pods per plant compared to the plants that had the fertilization split. Maximum yields of pods per plant (3.3), number of grains per pod (17.5), mass of 10 dry pods $(50 \mathrm{~g})$, mass of dry grains of 10 pods $(30 \mathrm{~g})$ and productivity of dry grains $\left(2.4 \mathrm{t} \mathrm{ha}^{-1}\right)$ were obtained with $60,100,60,100$ and $60 \mathrm{~kg} \mathrm{ha}^{-1}$ of $\mathrm{K}_{2} \mathrm{O}$, respectively. It is noteworthy that the provision of potassium fertilization in installments in the cultivation of cowpea beans is more appropriate and rational, as the nutrient will be available at the time of greatest metabolic demand from the plants and also, losses by leaching in the soil will be avoided.

Keywords: Potassium fertilization, dry grain production, Vigna unguiculata.

\section{INTRODUÇÃO}

Popularmente conhecido como feijão macassar, feijão-de-corda, feijão fradinho, o feijão-caupi (Vigna unguiculata (L.) Walp.), é leguminosa pertence à família da Fabaceae, é um dos principais componentes da dieta alimentar da população nas regiões Norte e Nordeste do Brasil, é uma das principais fontes proteicas das populações dessas regiões, que o consome sob a forma de grãos maduros ou grãos verdes ("feijão-verde" com teor de umidade entre 60 e 70\%) [1]. Todavia, também vem ganhando espaço e preferência entre os consumidores das demais regiões do Brasil.

Seu cultivo é predominante nas áreas semiáridas da região Nordeste, todavia, com o avanço tecnológico, a cultura tem ganhado maior expressividade econômica, com expansão de seu cultivo 
na região Centro-Oeste, principalmente por médios e grandes produtores com lavouras mais tecnificadas [2].

Embora o feijão-caupi seja uma cultura tropical com boa adaptação a solos de baixa fertilidade, o emprego de cultivares tradicionais com baixa capacidade produtiva, ausência de adoção de fertilizantes minerais e o baixo nível tecnológico adotado pelos produtores têm levado a produtividades baixas de grãos $[3,4]$. Por outro lado, em condições adequadas de fertilidade do solo, uso de adubações e cultivares melhoradas, o feijão-caupi pode alcançar até $3000 \mathrm{~kg} \mathrm{ha}^{-1} \mathrm{de}$ grãos $[5,6]$.

Conforme Cavalcanti (2008) [7], os teores adequados nas folhas do feijoeiro vigna são: $\mathrm{N}$ de 18 a $22 \mathrm{~g} \mathrm{~kg}^{-1}$, para $\mathrm{P}$ de 1,2 a $1,5 \mathrm{~g} \mathrm{~kg}^{-1}$, de 30 a $35 \mathrm{~g} \mathrm{~kg}^{-1} \mathrm{de} \mathrm{K}$, de 50 a $55 \mathrm{~g} \mathrm{~kg}^{-1}$ de Ca, de 5 a 8 $\mathrm{g} \mathrm{kg}^{-1}$ para o Mg e de 1,5 a 2,0 $\mathrm{g} \mathrm{kg}^{-1}$ para o S; e de 700 a $900 \mathrm{mg} \mathrm{kg}^{-1}$ de Fe, de 400 a $425 \mathrm{mg} \mathrm{kg}^{-}$ ${ }^{1}$ de Mn, para o B de 150 a $200 \mathrm{mg} \mathrm{kg}^{-1}$, de 40 a $50 \mathrm{mg} \mathrm{kg}^{-1}$ para o Zn e de 5 a $7 \mathrm{mg} \mathrm{kg}^{-1}$ para Cu.

Embora o potássio não participe diretamente da estrutura de moléculas constituintes do metabolismo da planta, está presente em diversas funções na mesma, destacando-se, a ativação de vários sistemas enzimáticos, principalmente os relacionados aos processos fotossintético e respiratório [8]. É um elemento essencial ao crescimento, desenvolvimento e maturação dos grãos e dos frutos dos vegetais. Na sua deficiência as plantas apresentam-se com diminuição do crescimento, pouco desenvolvimento radicular, flexibilidade e pouca resistência dos caules e maior suscetibilidade ao ataque de patógenos, além de formação de sementes e frutos de menor tamanho e de coloração menos intensa [9].

É possível que o feijoeiro-caupi possa absorver quantidades significativas de potássio, desde que em existam condições favoráveis. Todavia, algumas pesquisas têm apontado que a produtividade de grãos não tem refletido os altos teores de potássio presentes nos tecidos das plantas de feijão-vigna [10]. O teor de potássio nas folhas do feijão-caupi durante o período da granação decresceu de 25 para $12 \mathrm{~g} \mathrm{~kg}^{-1}$ de matéria seca e, manteve-se em $10 \mathrm{~g} \mathrm{~kg}^{-1}$ até o final do ciclo da cultura, entretanto, não foram observados incrementos na produtividade de grãos [11].

É possível haver um efeito negativo da adubação potássica no rendimento da cultura do feijão vigna, seja pela dose ou pela forma de aplicação. Mesmo sendo uma cultura moderadamente tolerante à salinidade, tolerando condutividade elétrica da água de irrigação de até $3,3 \mathrm{dS} \mathrm{m}^{-1}$, a partir da qual verifica-se queda na produtividade [12]. Para Kluthcoushi (1999) [13], o uso de doses elevadas de fertilizantes salinos no ato da semeadura podem causar injúrias às plântulas, podendo ocorrer diminuição de até $50 \%$ no stand de plantas, vindo a prejudicar o rendimento da cultura do feijoeiro comum.

O feijoeiro-caupi pode ser influenciado por vários fatores tais como, a dose e forma de distribuição do adubo, o tipo de solo, se irrigado ou não é a fenologia da planta [14]. O teor de K disponível no solo, sua textura e a espécie cultivada, são alguns dos fatores que determinam o modo de aplicação e a quantidade de fertilizantes potássicos a serem aplicados [15]. Faz-se necessária a aplicação parcelada da adubação potássica pois a adição de doses elevadas de óxido de potássio $\left(\mathrm{K}_{2} \mathrm{O}\right)$ no momento da semeadura causará um excesso na concentração salina, que poderá prejudicar a germinação e o crescimento inicial da planta [16].

Com a finalidade de se obter referências para a geração de informações que atendam às necessidades dos produtores em melhorar o desempenho do cultivo de feijão-caupi em regiões semi-áridas do Nordeste brasileiro, objetivou-se avaliar o efeito da forma de parcelamento das doses de fertilizantes potássicos sobre a produção de feijão-caupi cultivar Pingo de Ouro.

\section{MATERIAL E MÉTODOS}

O experimento foi conduzido na área experimental da Universidade Federal do Oeste da Bahia,

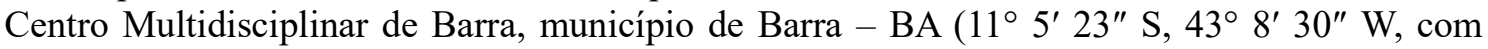
altitude média de 398 metros). O clima da região segundo a classificação de Köeppen, é do tipo é Aw, clima tropical com estação seca. O ensaio ocorreu no período de agosto a outubro de 2018 , e durante o período as temperaturas média, mínima e máxima foram $26,9,19,1$ e $34,4{ }^{\circ} \mathrm{C}$, respectivamente, e a precipitação acumulada foi de $0,0 \mathrm{~mm}$.

A análise do solo da área experimental (Profundidade de 0-20 cm) apresentou as características: $\mathrm{pH} \mathrm{em} \mathrm{H}_{2} \mathrm{O}=5,5 ; \mathrm{P}=3,0 \mathrm{mg} \mathrm{dm}^{-3}$ (Mehlich 1); $\mathrm{K}=46 \mathrm{mg} \mathrm{dm}^{-3} ; \mathrm{Ca}^{2+}=0,9 \mathrm{cmol}_{\mathrm{c}}$ 
$\mathrm{dm}^{-3} ; \mathrm{Mg}^{2+}=0,2 \mathrm{cmol}_{\mathrm{c}} \mathrm{dm}^{-3} ; \mathrm{H}+\mathrm{Al}=3,3 \mathrm{cmol}_{\mathrm{c}} \mathrm{dm}^{-3}, \mathrm{~S}=1,55 \mathrm{cmol}_{\mathrm{c}} \mathrm{dm}^{-3}, \mathrm{~V}=57 \%$ e $\mathrm{M} \cdot \mathrm{O}=1,24$ $\mathrm{g} \mathrm{kg}^{-1}$. Granulometria (\%): Areia $=74$, Silte $=11$ e Argila $=15$.

O preparo do solo foi com uma gradagem e abertura manual dos sulcos de plantio com auxílio de enxadas. A fertilização da cultura foi realizada com base na análise química do solo e as recomendações para feijão-caupi, conforme Cravo et al. (2007) [17]. Na adubação de plantio, os nutrientes foram distribuídos e incorporados em sulcos que estavam localizados a $5 \mathrm{~cm}$ ao lado e a $5 \mathrm{~cm}$ mais profundo que o sulco de semeadura. Foram aplicados $75 \mathrm{~kg} \mathrm{ha}^{-1} \mathrm{de}_{2} \mathrm{O}_{5} ; 20 \mathrm{~kg} \mathrm{ha}^{-1}$ de $\mathrm{N}$ e o $\mathrm{K}_{2} \mathrm{O}$ de acordo com os tratamentos adotados no experimento. Utilizaram-se como fontes de $\mathrm{N}, \mathrm{P}$ e K, uréia, superfosfato simples e cloreto de potássio, respectivamente. Aplicaram-se ainda, no plantio, $15 \mathrm{~kg} \mathrm{ha}^{-1}$ de sulfato de zinco, $10 \mathrm{~kg} \mathrm{ha}^{-1}$ de bórax, $10 \mathrm{~kg} \mathrm{ha}^{-1}$ de sulfato de cobre e $0,5 \mathrm{~kg} \mathrm{ha}^{-1}$ de molibdato de amônio. Foi realizada uma adubação de cobertura com $\mathrm{N}$, e com o $\mathrm{K}$ conforme os tratamentos adotados. A cobertura foi no início do florescimento, o qual ocorreu por volta dos 45 dias após a emergência (DAE) das plântulas. Foram aplicados $45 \mathrm{~kg} \mathrm{ha}^{-1}$ de N e $1 / 2$ da dose de $\mathrm{K}_{2} \mathrm{O}$, conforme o tratamento, e as fontes de $\mathrm{N}$ e $\mathrm{K}$, foram uréia e cloreto de potássio, respectivamente.

O delineamento experimental foi em blocos ao acaso, em esquema fatorial $2 \times 5$, compreendendo dois modos de aplicação da adubação potássica (toda a dose no plantio e parcelado com $1 / 2$ na semeadura e $1 / 2$ em cobertura no início do florescimento) e cinco doses de $\mathrm{K}_{2} \mathrm{O}\left(0,40,60,80\right.$ e $100 \mathrm{~kg} \mathrm{ha}^{-1}$ de $\left.\mathrm{K}_{2} \mathrm{O}\right)$, com quatro repetições.

Utilizou-se a cultivar de feijão-caupi Pingo de Ouro. A semeadura foi realizada manualmente no espaçamento de $0,5 \times 0,20 \mathrm{~m}$ em sulco contínuo a $3 \mathrm{~cm}$ de profundidade, e foram colocadas duas sementes para posterior desbaste que se efetuou 15 dias após a emergência das plântulas. As parcelas experimentais foram constituídas por seis linhas de 2,0 $\mathrm{m}$ de comprimento, em que as quatro linhas centrais compuseram a área útil de $2,0 \mathrm{~m}^{2}$. Foram consideradas úteis as 20 plantas centrais, excetuando-se três plantas em cada extremidade.

Durante a condução do experimento realizaram-se capinas manuais para o controle de plantas daninhas. A irrigação foi realizada por meio de microaspersão, aplicando-se lâminas em torno ente 5 e $10 \mathrm{~mm}$, baseadas na evaporação do tanque classe A. Foram realizadas seis pulverizações com deltamethrina (126 $\mathrm{ml} \mathrm{ha}^{-1}$ ) para controle de pulgões (Aphis craccivora), mosca branca (Bemisia tabaci biótipo B) e cigarrinha verde (Empoasca kraemeri).

As colheitas, em número de três, foram realizadas manualmente a partir dos 70 dias após a emergência das plântulas, quando as plantas apresentavam amarelecimento, quando vagens estavam com a casca seca e apresentavam coloração palha, indicativo do ponto de colheita [18]. Nessa etapa, nas plantas selecionadas foram avaliadas quanto a: número de vagens por planta, comprimento de vagem $(\mathrm{cm})$, número de grãos por vagem, peso de 100 grãos $(\mathrm{g})$, massa de 10 vagens $(\mathrm{g})$, massa dos grãos de 10 vagens $(\mathrm{g})$ e produtividade $\left(\mathrm{t} \mathrm{ha}^{-1}\right)$. As avaliações do comprimento de vagem foram obtidas com a média de 10 vagens de cada parcela.

Os dados foram submetidos às análises de variância, teste de Tukey ao nível de $5 \%$ de probabilidade para comparação das médias e de regressão para as doses de $\mathrm{K}_{2} \mathrm{O}$ que foram selecionados os modelos significativos que apresentaram maior coeficiente de determinação $\left(\mathrm{R}^{2}\right)$, todas as análises foram realizadas utilizando-se o software SISVAR 5.4 [19].

\section{RESULTADOS E DISCUSSÃO}

Ocorreu interação entre forma de aplicação do $\mathrm{K}$ e as doses de $\mathrm{K}_{2} \mathrm{O}$ apenas para o comprimento das vagens, no qual a aplicação da dose de $100 \mathrm{~kg} \mathrm{ha}^{-1}$ parcelada proporcionou a produção de aproximadamente 22 vagens por planta (Figura 1). 


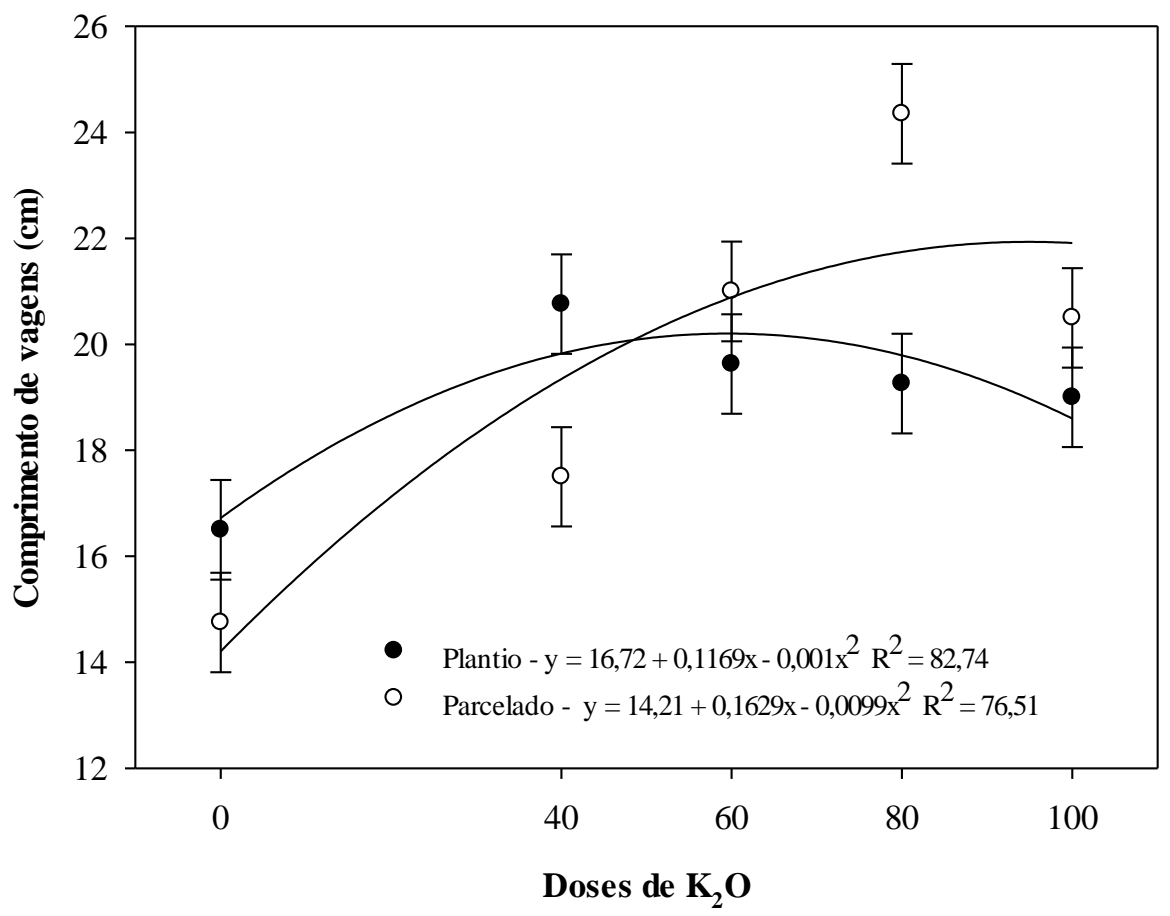

Figura 1. Comprimento de vagens de feijão-caupi cultivar Pingo de Ouro em função das doses de $\mathrm{K}_{2} \mathrm{O} e$ da forma de aplicação em dose total no plantio (•) ou parcelado $1 / 2$ no plantio e $1 / 2$ no início do florescimento ( $)$.

Ocorreu efeito isolado das doses de $\mathrm{K}_{2} \mathrm{O}$ e forma de aplicação para todas as variáveis (Tabela 1 e Figuras 2, 3, 4 e 5). O fornecimento de toda à adubação potássica no sulco de semeadura proporcionou aumento de $6,67 \%$ no número de vagens por planta em comparação com plantas que tiveram adubação parcelada. As demais variáveis não apresentaram influência do modo de aplicação das doses de $\mathrm{K}_{2} \mathrm{O}$ (Tabela 1).

Pode ser inferido que o parcelamento da maior dose de $\mathrm{K}_{2} \mathrm{O}$ favoreceu o maior tamanho das vagens por dois motivos: na fase vegetativa devido à maior disponibilidade do $\mathrm{K}$ contribuindo para as reações metabólicas e o maior crescimento da área foliar fotossinteticamente ativa, e, na fase reprodutiva, com suprimento adequado atendendo as reações metabólicas e a demanda dos drenos em expansão. Essa nossa afirmativa se fundamenta na assertiva de Pedroso Neto e Rezende (2005) [20], que alcançaram maior produtividade em soja quando adotadas doses crescentes e parceladas de $\mathrm{K}$, devido ao fato de ocorrer maior acúmulo de $\mathrm{K}$ no início do ciclo para uso na fase reprodutiva. Desse modo, acredita-se que ele pode ter acontecido com o feijão-caupi nessas condições de experimento, favorecendo a aplicação parcelada do macronutriente. 
Tabela 1. Número de grãos por vagem, número de vagens por planta, massa de 10 vagens, massa de grãos contidos em 10 vagens, peso de 100 grãos e produtividade de feijão-caupi cultivar Pingo de Ouro em função do modo de aplicação das doses de $\mathrm{K}_{2} \mathrm{O}$, se em dose total no plantio ou parcelado $1 / 2$ no plantio e $1 / 2$ no início do florescimento.

\begin{tabular}{|c|c|c|c|c|c|c|}
\hline $\begin{array}{l}\text { Modo de } \\
\text { aplicação } \\
\text { do } \mathrm{K}_{2} \mathrm{O}\end{array}$ & $\begin{array}{c}\text { Grãos/va } \\
\text { gem }^{\text {ns }}\end{array}$ & $\begin{array}{l}\text { Vagens/p } \\
\text { lanta** }\end{array}$ & $\begin{array}{c}\text { Massa de } \\
10 \text { vagens } \\
(\mathrm{g})^{\mathrm{ns}}\end{array}$ & $\begin{array}{l}\text { Massa dos } \\
\text { grãos de } 10 \\
\text { vagens }(\mathrm{g}){ }^{\mathrm{ns}}\end{array}$ & $\begin{array}{c}\text { Peso de } \\
100 \text { grãos } \\
\text { (g) }{ }^{\text {ns }}\end{array}$ & $\begin{array}{l}\text { Produtividade } \\
\quad\left(\mathrm{t} \mathrm{ha}^{-1}\right)^{\mathrm{ns}}\end{array}$ \\
\hline $\begin{array}{l}\text { Dose total } \\
\text { no plantio }\end{array}$ & $15,95 \mathrm{a}$ & $3,52 \mathrm{a}$ & $47,45 \mathrm{a}$ & $28,69 \mathrm{a}$ & $17,36 \mathrm{a}$ & $2,03 \mathrm{a}$ \\
\hline Parcelado & $16,80 \mathrm{a}$ & $3,30 \mathrm{~b}$ & $44,69 \mathrm{a}$ & $30,77 \mathrm{a}$ & $18,59 \mathrm{a}$ & $2,01 \mathrm{a}$ \\
\hline DMS & 1,13 & 0,21 & 3,18 & 2,52 & 3,27 & 0,16 \\
\hline CV (\%) & 10,73 & 9,58 & 12,74 & 13,06 & 18,00 & 12,90 \\
\hline
\end{tabular}

Médias seguidas pela mesma letra minúscula na coluna, não diferem entre si pelo Teste de Tukey ao nível de $5 \%$ de probabilidade. ** ou *: significativo ao nível de $1 \%$ ou de $5 \%$ de probabilidade pelo teste $F$. DMS: diferença mínima significativa. CV (\%): coeficiente de variação.

Observou-se respostas quadráticas e significativas das características avaliadas $(\mathrm{P}<0,05)$ às doses de $\mathrm{K}_{2} \mathrm{O}$. As produções máximas de vagens por planta $(3,3)$, número de grãos por vagem $(17,5)$, massa de 10 vagens secas $(50 \mathrm{~g})$, massa de grãos secos de 10 vagens $(30 \mathrm{~g})$ e produtividade de grãos secos $\left(2,4 \mathrm{t} \mathrm{ha}^{-1}\right)$ foram obtidas, respectivamente com 60, 100, 60, 100 e $60 \mathrm{~kg} \mathrm{ha}^{-1} \mathrm{de}^{\mathrm{a}}$ $\mathrm{K}_{2} \mathrm{O}$ (Figuras 2, 3, 4 e 5).

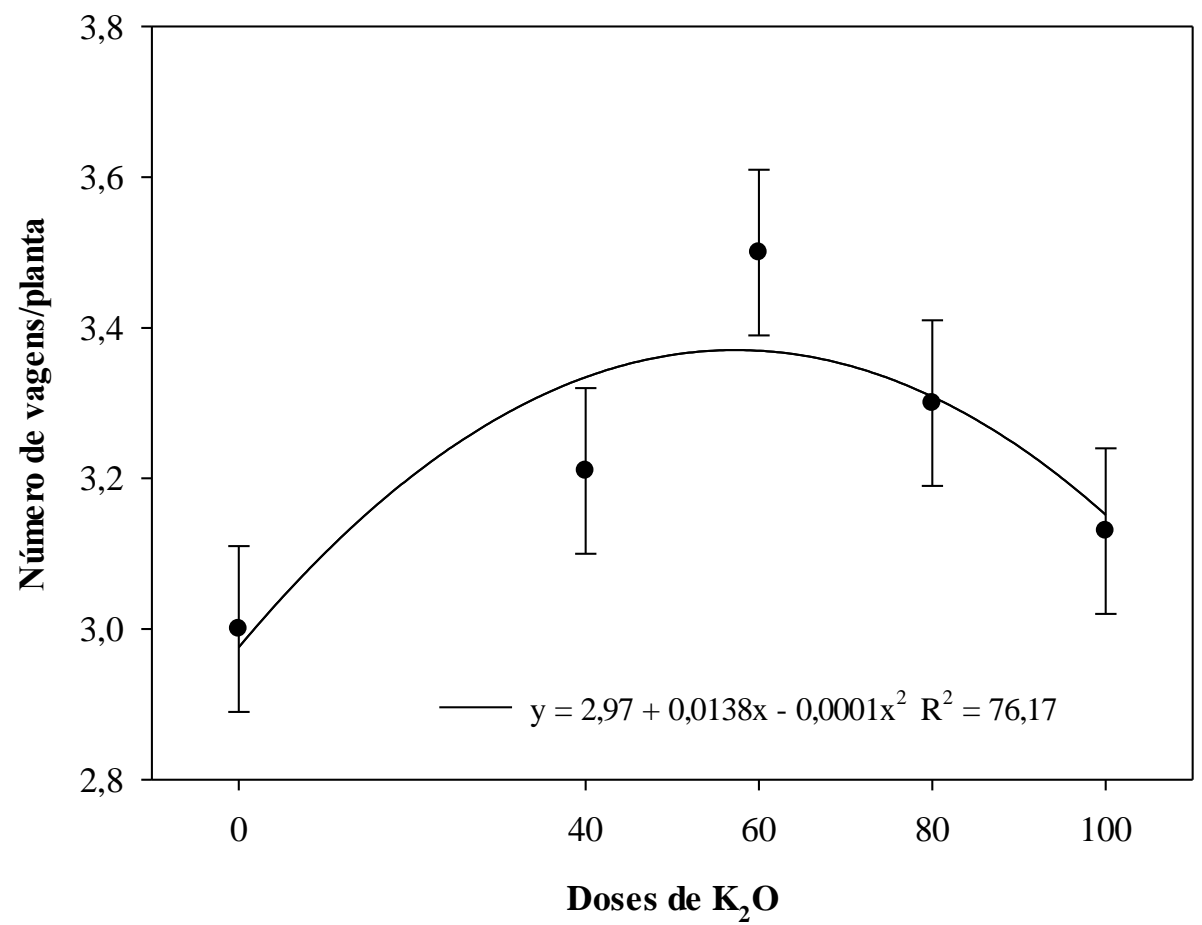

Figura 2. Número de vagens por planta (•) de feijão-caupi cultivar Pingo de Ouro em função das doses de $\mathrm{K}_{2} \mathrm{O}$ aplicadas. 


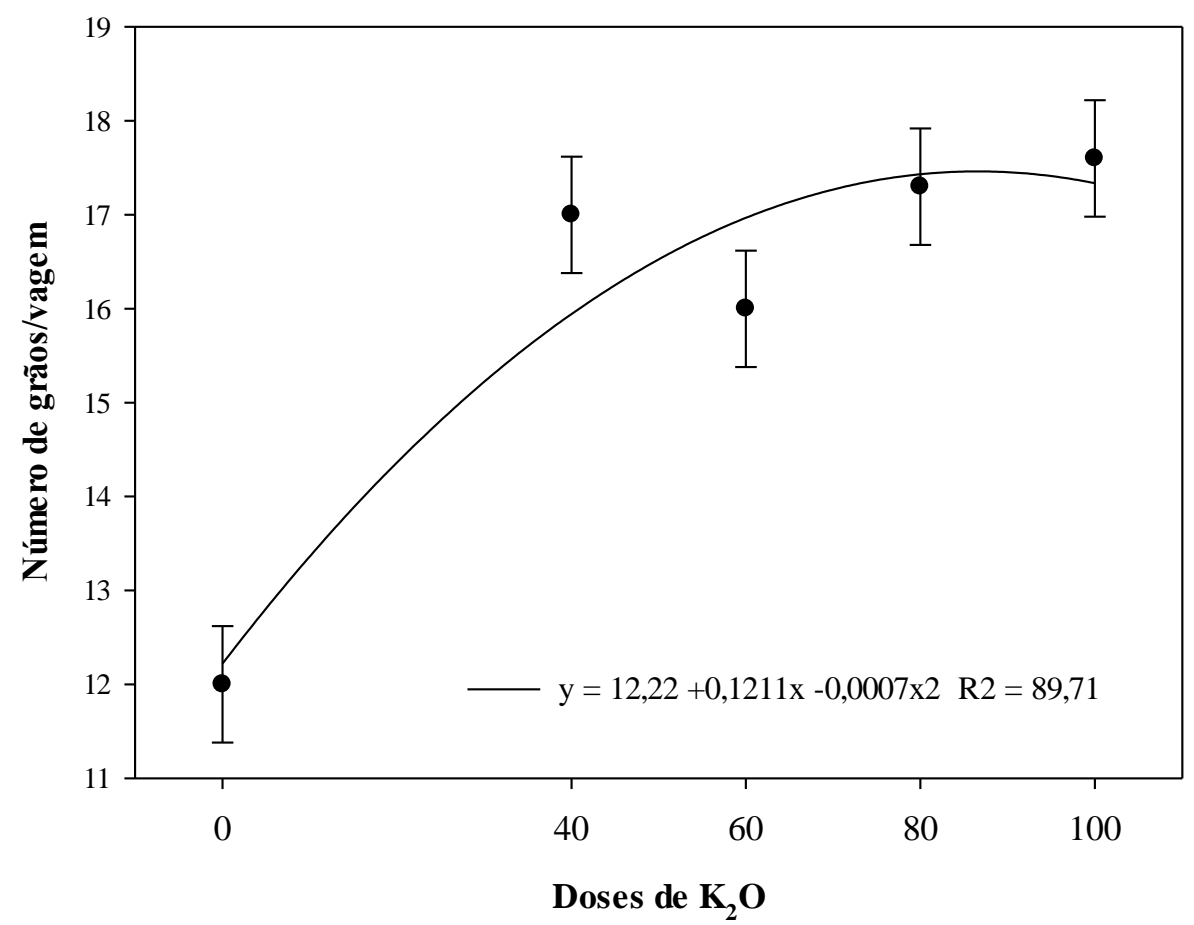

Figura 3. Número de grãos por vagem (•) de feijão-caupi cultivar Pingo de Ouro em função das doses de $\mathrm{K}_{2} \mathrm{O}$ aplicadas.

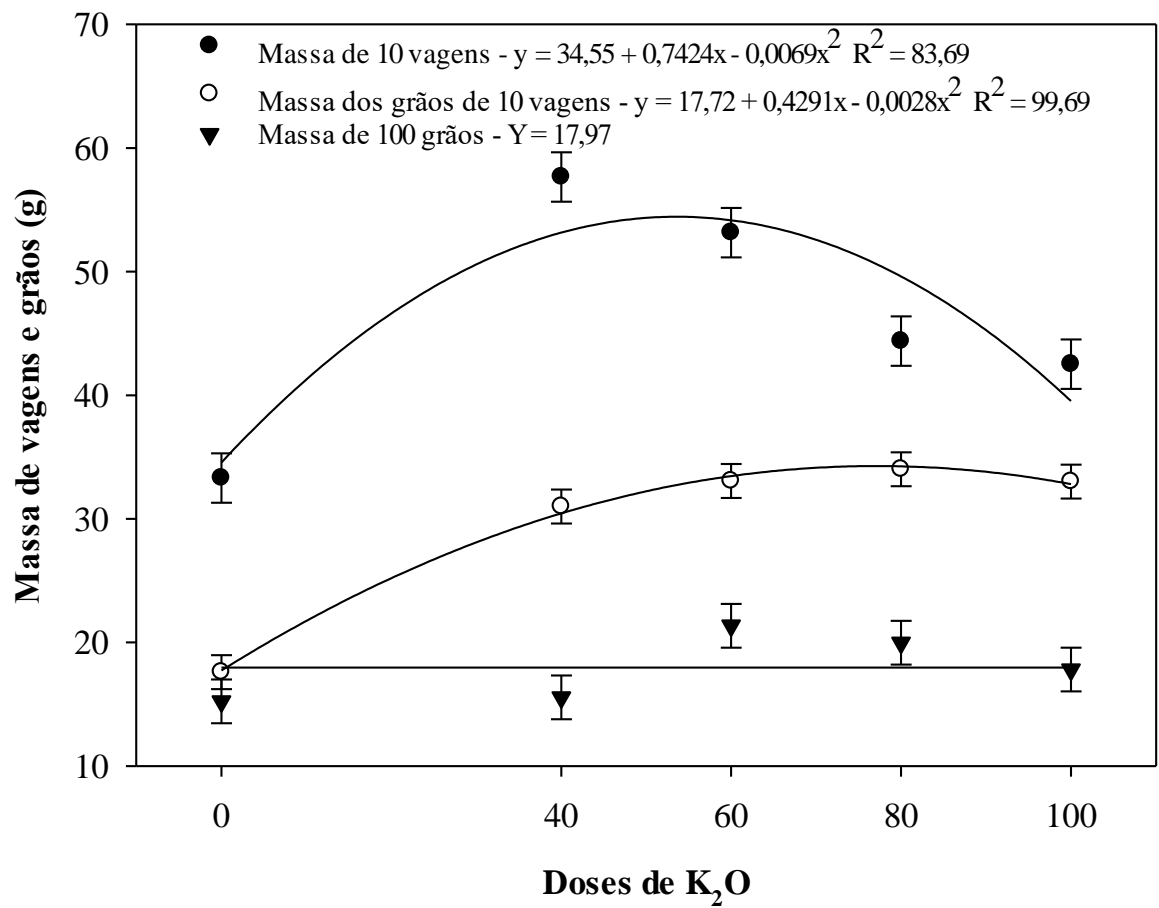

Figura 4. Massa de 10 vagens (•), massa de grãos de 10 vagens (०) e massa de 100 grãos ( $\mathbf{\nabla}$ ) de feijãocaupi cultivar Pingo de Ouro em função das doses de $\mathrm{K}_{2} \mathrm{O}$ aplicadas. 


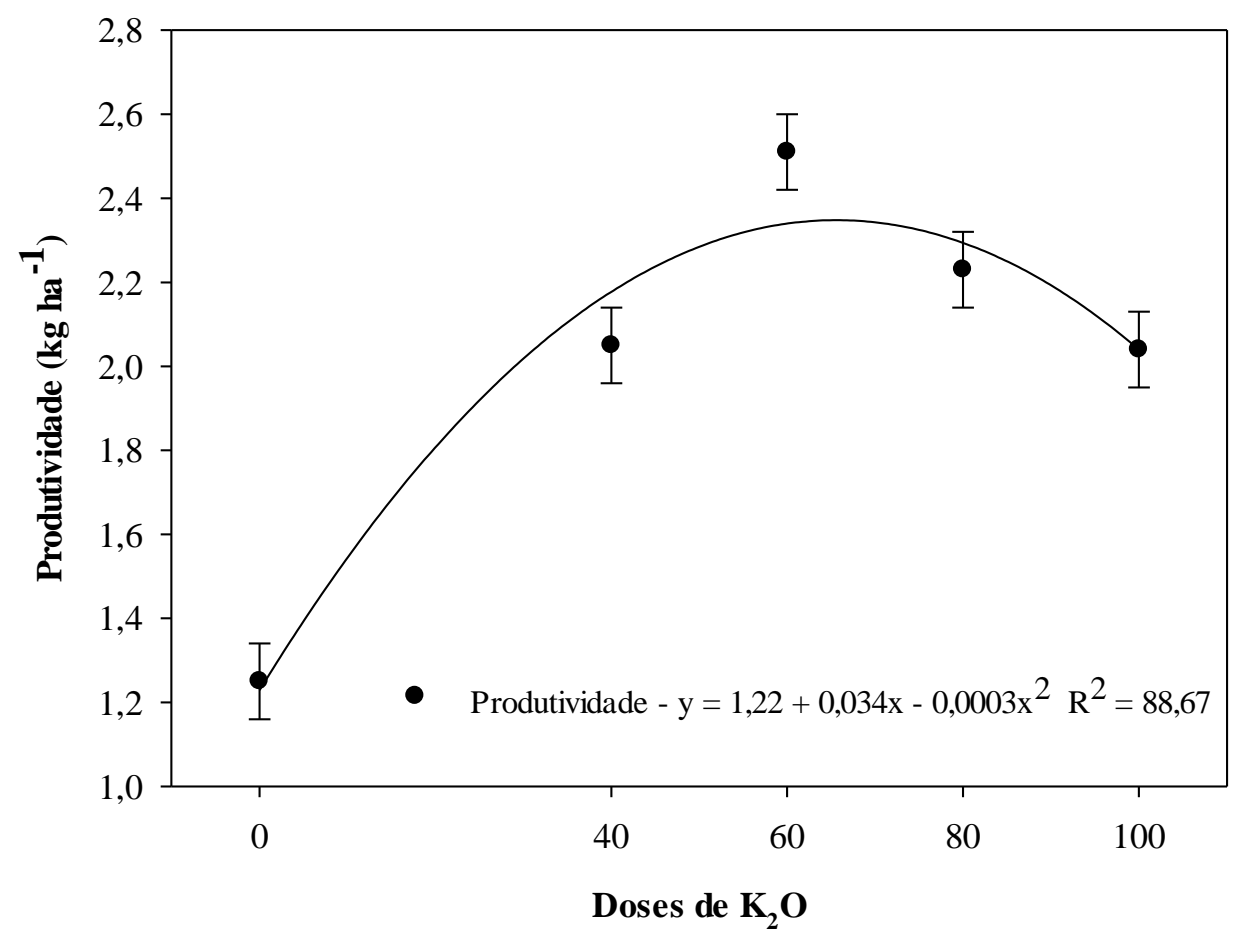

Figura 5. Produtividade (•) de feijão-caupi cultivar Pingo de Ouro em função das doses de $\mathrm{K}_{2} \mathrm{O}$ aplicadas.

Os presentes resultados contradizem Melo et al. (2005) [10], que apontam uma resposta rara à adubação potássica por parte do feijão-caupi. Resposta parecida de produtividade foi encontrada por Veloso et al. (2013) [21] estudando adubação fosfatada e potássica, e que a produção máxima foi obtida com a dose de $70 \mathrm{~kg} \mathrm{ha}^{-1}$ de $\mathrm{K}_{2} \mathrm{O}$ para a cultura do feijão-caupi. Também Oliveira et al. (2009) [5] encontraram produtividades máximas estimadas de grãos secos com aplicação de 170 $\mathrm{kg} \mathrm{ha}^{-1}$ de $\mathrm{K}_{2} \mathrm{O}$.

O teor crítico de potássio entre 20 e $40 \mathrm{~kg} \mathrm{ha}^{-1}$ é atribuído como o ideal ao desenvolvimento normal do feijão-caupi [10]. Portanto, as doses de $\mathrm{K}_{2} \mathrm{O}$ desta pesquisa $\left(60 \mathrm{~kg} \mathrm{ha}^{-1}\right)$ que aqui foram superiores às necessárias para proporcionar produtividades máximas $\left(2,4 \mathrm{t} \mathrm{ha}^{-1}\right)$ à cultura do feijoeiro caupi, possivelmente, tenha relação com a capacidade de absorção do potássio pelas leguminosas, desde que existam condições favoráveis, e posterior remobilização para os drenos de interesse.

Acredita-se que se fornecidas doses de $\mathrm{K}_{2} \mathrm{O}$ superiores àquelas consideradas ótimas para as máximas produtividades de grãos, poderá ocorrer a redução da produtividade de grãos devido ao efeito antagônico sobre a absorção de outros cátions, pois o K é altamente competitivo em relação ao $\mathrm{Ca}, \mathrm{Mg}, \mathrm{N}$ e $\mathrm{P}$, influenciando negativamente o desenvolvimento e produção das plantas [22].

Infere-se que, a maior produtividade de grãos secos esteja relacionada à maior disponibilidade de K para atender aos processos fisiológicos de translocação de fotossimilados e enchimento de grãos, contribuindo para maior acúmulo de biomassa e obtenção de grãos mais pesados. Pedroso Neto e Rezende (2005) [20] explicam que a maior absorção de K em plantas de soja ocorre na fase vegetativa, geralmente entre 44 e 63 dias após emergência, e se as adubações de cobertura forem efetuadas aos 30 dias após a semeadura poderão favorecer aumento na produtividade, pois o nutriente estará mais disponível no momento de maior demanda pelas plantas.

Também se destaca que a capacidade de remobilização do teor de potássio acumulado nas folhas tenha sido um dos responsáveis pelo ganho de produtividade, uma vez que Sampaio e Brasil (2009) [11] enfatizam ocorrer uma redução no teor de potássio presente nas folhas do feijão-vigna durante o período da granação.

Nas condições de solos tropicais, o potássio é um dos nutrientes mais limitantes à produção, sendo indispensável sua presença nas formulações de fertilizantes, desse modo, é imprescindível 
a presença das adubações potássicas para assegurar o desenvolvimento e produção das plantas [23].

O K é indispensável para o desenvolvimento das plantas, cujas principais funções estão relacionadas aos processos fisiológicos vitais como fotossíntese, translocação e balanço iônico, mas ao mesmo tempo é bastante móvel no solo, desse modo, destaca-se aqui que, mesmo não havendo diferença estatística quanto o parcelamento, assegurar a oferta de potássio parcelado para que esteja disponível para atender a demanda metabólica das plantas e evitar perdas por lixiviação no solo, deve ser a maneira mais adequada e racional para uso da adubação potássica no cultivo do feijoeiro caupi.

\section{CONCLUSÃO}

A adição do potássio aumentou o rendimento do feijão-caupi cultivar Pingo de Ouro.

A aplicação da dose de $100 \mathrm{~kg} \mathrm{ha}^{-1}$ parcelada permitiu a produção de aproximadamente 22 vagens por planta.

O fornecimento de toda à adubação potássica no sulco de semeadura proporcionou aumento de $6,67 \%$ no número de vagens por planta em relação às plantas que tiveram a adubação parcelada. A maior produtividade de grãos foi obtida com a aplicação de $60 \mathrm{~kg} \mathrm{ha}^{-1}$ de $\mathrm{K}_{2} \mathrm{O}$.

Não houve influência da forma de parcelamento da adubação potássica sobre a produtividade de feijão-caupi, todavia, acredita-se que se realizado o parcelamento serão reduzidas as perdas do $\mathrm{K}$ por lixiviação e as plantas o aproveitarão de maneira mais eficiente na fase de florescimento e enchimento de grãos.

\section{REFERÊNCIAS BIBLIOGRÁFICAS}

1. Souza LSB, Moura MSB, Sediyama GC, Silva TGF. Eficiência do uso da água das culturas do milho e do feijão-caupi sob sistemas de plantio exclusivo e consorciado no semiárido brasileiro. Rev Bragantia. 2011 Jul;70(3):715-721, doi:10.1590/S0006-87052011000300030

2. Freire Filho FR. Feijão-caupi no Brasil: produção, melhoramento genético, avanços e desafios tecnológicos. Teresina: Embrapa Meio-Norte; 2011. 84 p.

3. Vesterager JM, Nielsen NE, Jensen HH. Effects of cropping history and phosphorus source on yield and nitrogen fixation in sole and intercropped cowpea- maize systems. Nutr Cycling Agroecosyst. 2008 Jan;80(1):61-73.

4. Matos Filho CHA, Gomes RLF, Rocha MM, Freire Filho FR, Lope ACA. Potencial produtivo de progênies de feijão-caupi com arquitetura ereta de planta. Ciên Rural. 2009 Mar;30(2):348-354.

5. Oliveira PA, Silva JA, Lopes EL, Silva EE, Araújo LHA, Ribeiro VV. Rendimento produtivo e econômico do feijão-caupi em função de doses de potássio. Lavras, Ciên Agrotec. 2009 Mar;33(2):629634.

6. Oliveira PA, Silva JA, Alves AU, Dorneles CSM, Alves AU, Oliveira ANP, Cardoso EA, Cruz IS. Rendimento de feijão-vagem em função de doses de $\mathrm{K}_{2} \mathrm{O}$. Hortic Bras. 2007 Jan;25(1):29-33.

7. Cavalcanti FJA. Recomendações de adubação para o Estado de Pernambuco: $2^{\mathrm{a}}$ aproximação. 3.ed. Recife, IPA; 208. 212 p.

8. Taiz L, Zeiger E. Fisiologia vegetal. 5. ed. Porto Alegre: Artmed; 2013. 918 p.

9. Ernani PR, Almeida JA, Santos FC. Potássio. In: Novais RF, Alvarez VVU, Barros NF, Fontes RLF, Cantarutti RB, Neves JCL. Fertilidade do solo. Viçosa: UFV; 2007. 1017 p.

10. Melo FB, Cardoso MJ, Salviano AAC. Fertilidade do solo e adubação. In: avanços tecnológicos. Brasília, DF: Embrapa Meio-norte; 2005. p. 228-242. Feijão-Caupi:

11. Sampaio LS, Brasil EC. Exigência nutricional do feijão-caupi. In: Congresso Nacional De Feijão-Caupi, 2., 2009, Belém, PA. Da agricultura de subsistência ao agronegócio: Anais. Belém, PA: Embrapa Amazônia Oriental, 2009:56-72. 1 CD-ROM. http://ainfo.cnptia.embrapa.br/digital/bitstream/item/59651/1/Exigencia.pdf. Acessado em 20 de janeiro de 2020.

12. Ayers RS, Westcot DW. A qualidade da água na agricultura. Campina Grande: UFPB; 1999.153 p.

13. Kluthcouski J. Efeito salino, causado por fertilizantes, no sistema de plantio direto sobre as culturas do feijão, soja e arroz. In: Reunião Nacional de Pesquisa de Feijão (1999: Salvador). Resumos. Salvador: Embrapa Arroz e Feijão, 1999:797-800.

14. Sguario-Jr JC, Daros, E, Pauletti V, Ronzelli-Jr P, Koehler HS, Oliveira RA. Doses e formas de aplicação de potássio na cultura do Feijoeiro em sistema de plantio direto na palha. Sci Agraria. 2006 Jan;7(1-2):9-14, doi:10.5380/rsa.v7i1.7265 
15. Uchôa SCP, Ivanoff MEEA, Alves JMA, Sediyama T, Martins SA. Adubação de potássio em cobertura nos componentes de produção de cultivares de girassol. Rev Ciên Agron. 2011 Jan;42(1):8-15, doi:10.1590/S1806-66902011000100002

16. Vilela L, Sousa DMG, Silva JE. Adubação potássica. In: SOUSA, D. M. G. e LOBATO, E., Eds. Cerrado: correção do solo e adubação. 2.ed. Brasília, Embrapa; 2004. p.169-183.

17. Cravo MS, Viegas IJM, Brasil EC. Recomendações de adubação e calagem para o Estado do Pará. 1. ed. Belém: Embrapa Amazônia Oriental; 2007. 262 p.

18. Menezes Júnior JAN Rocha MM, Silva KJD, Vale JC, Bertini CHCM. Colheita. In: Vale JC, Bertini C, Borém A, editores. Feijão-Caupi: do plantio à colheita. Viçosa, MG: Ed. UFV; 2017. p. 244-267.

19. Ferreira DF. Sisvar: a computer statistical analysis system. Ciên Agrotecnol. 2011 Nov;35(6):10391042, doi:10.1590/S1413-70542011000600001

20. Pedroso Neto JC, Rezende PM. Doses e modos de aplicação de potássio na produtividade de grãos e qualidade de semente de soja (Glycine max (L.) Merrill). Rev Uberaba. 2005 Jan;2:27-36.

21. Veloso CAC, Silva AR, Martinez, GB, El-Husny JC, Carvalho EJM. Adubação fosfatada e potássica para a cultura do feijão-caupi no Nordeste Paraense. In: Congresso Brasileiro de Ciência do Solo, 34. , Florianópolis, 2013. Resumos expandidos... Viçosa: Sociedade Brasileira de Ciência do Solo, 2013:1-4.

22. Galvão JR, Fernandes AR, Melo NC, Silva VFA, Albuquerque MPF. Sistemas de manejo e efeito residual do potássio na produtividade e nutrição do feijão-caupi. Rev Caatinga. 2013 Abr;26(2):41-49.

23. Kaminski J, Brunetto G, Moterle DF, Rheinheimer DS. Depleção de formas de potássio do solo afetada por cultivos sucessivos. Rev Bras Ciên Solo. 2007 Set;31(5):1003-1010, doi:10.1590/S010006832007000500017 